\title{
A experimentação no teatro contemporâneo alemão
}

Suzana Campos de A. Mello*

\begin{abstract}
This article deals with experimentation in contemporary German theatre, making a survey of experimental elements in German and Brazilian stagings, particularly of Shakespearean texts, which took place from 1990 to the present. The survey has been based on the analysis of reviews published in newspapers and magazines in both countries, and also on video recordings of two German and one Brazilian stagings. The article describes the concepts of experimentation and convention developed in the study, presents the results of the research and discusses the appropriation of these elements, especially the experimental ones, in the contemporary Brazilian and German Theater.
\end{abstract}

Keywords: Experimentation; Convention; Contemporary Theater; Shakespeare; Theatre Aesthetics.

Zusammenfassung: Dieser Artikel beschäftigt sich mit den experimentellen Aspekten des deutschen Theaters der Gegenwart. Ziel der Untersuchung war

\footnotetext{
Suzana Campos de A. Mello (E-mail: suzanacam@yahoo.com) é aluna do curso de pós-graduação da Área de Língua e Literatura Alemã da FFLCH-USP e desenvolveu o projeto de iniciação científica "A Experimentação no Teatro Contemporâneo Alemão" como bolsista da FAPESP, sob a orientação do Prof. Dr. Helmut Galle.
} 
zunächst eine Aufstellung von experimentellen Elementen in deutschen und brasilianischen Inszenierungen seit 1990, insbesondere von Shakespeare-Stücken. Mit den Daten dieser Aufstellung wurde ein Vergleich und eine Analyse der Inszenierungen in beiden Ländern durchgeführt. Die Aufstellung wurde realisiert mit Hilfe von Rezensionen, die in Zeitungen und Zeitschriften in Brasilien und Deutschland veröffentlicht wurden, und ergänzt durch eigene Beobachtungen zu Videoaufzeichnungen von zwei deutschen und einer brasilianischen Inszenierung. Der Beitrag beschreibt die Begriffe des „Experimentellen” und der „Konvention”, wie sie in der Untersuchung entwickelt wurden. Er stellt die Ergebnisse der Untersuchung vor und reflektiert die Eignung dieser Begriffe, besonders des Experimentellen, im Gegenwartstheater in Brasilien und Deutschland.

Stichwörter: Experimentelle Inszenierung; Konventionelle Inszenierung; Theater der Gegenwart; Shakespeare; Theaterästhetik.

Palavras-chave: Experimentação; Convenção; Teatro contemporâneo; Shakespeare; Estética teatral.

\section{Introdução}

O título desse artigo é o mesmo dado à pesquisa de iniciação científica que foi desenvolvida e que teve o fomento da FAPESP no biênio 2003-2004, pela Área de Língua e Literatura Alemã da Faculdade de Filosofia, Letras e Ciências Humanas da Universidade de São Paulo. Ele visa à apresentação de alguns pontos tratados naquele estudo e, a partir deles, à proposição de reflexões acerca da experimentação no teatro contemporâneo alemão.

Antes da apresentação geral da pesquisa, objetivo, metodologia, levantamento de dados e comentário sobre a análise, gostaríamos de abordar brevemente duas palavras-chave que constam do título desse texto: experimentação e contemporâneo. Elas foram balizas importantes na elaboração do projeto não só pelo fato de constarem, respectivamente, na metodologia da pesquisa e na delimitação do corpus analisado, mas, principalmente, pelos questionamentos que suscitaram ao longo de todo o estudo das relações entre experimentação vs convenção e contemporaneidade vs classicidade. 
Quando refletimos sobre o teatro, como consideramos uma peça (montagem ou texto) contemporânea? E, nos dias de hoje, o que seria a experimentação? E, ainda, o que seria essa experimentação dentro de uma contemporaneidade?

Os conceitos de experimentação e convenção, estabelecidos na pesquisa, serão tratados após a apresentação geral do projeto, e partiremos da relação entre contemporaneidade e classicidade para fazer essa apresentação.

Para a realização do estudo, que consistiu na análise de resenhas de peças alemãs e brasileiras, foi necessário delimitar o período que seria abordado na pesquisa. Houve a opção de tratar das peças encenadas após o ano de 1990, ou seja, após a queda do muro de Berlim e ano da reunificação da Alemanha, tendo em vista que o teatro alemão vivia, então, uma nova fase, livre das tensões ideológicas das décadas anteriores, quando o país ficou dividido em dois blocos: o capitalista e o socialista, fato que influenciava as produções artísticas, principalmente na ex-Alemanha Oriental.

Para que a escolha do corpus fosse feita, a comparação entre a práxis teatral dos dois países? Alemanha e Brasil? baseou-se na escolha de um dramaturgo que não desempenhasse um papel central na construção da identidade nacional das respectivas literaturas, e, ainda, que fosse montado freqüentemente, tanto no Brasil quanto na Alemanha, e por esses motivos William Shakespeare foi escolhido. Assim, a escolha recaiu sobre um autor clássico.

Nos dias de hoje, muitos recursos? considerados "experimentais"? são usados em montagens, principalmente de textos clássicos, e acreditamos que um dos objetivos desse uso, em um mundo pós-moderno, seja a sobrevivência do próprio teatro e/ou do clássico. Parte desses recursos remetem à teorias e práticas teatrais que, desde as vanguardas do início do século XX, começaram a suplantar as formas convencionais do teatro burguês do século XIX.

A partir disso, para a análise das peças, foram estabelecidos os conceitos de convenção e experimentação, que foram constituídos a partir dos elementos contidos nos textos (os registos do dramaturgo: extra-diálogos e/ou narativa) e suas transposições cênicas (resoluções dadas pelo diretor a 
esses elementos, bem como o acréscimo de outros por parte dos encenadores).

O objetivo principal da pesquisa foi a realização de uma amostra de elementos "experimentais" no teatro das duas culturas estudadas, com um enfoque específico na Alemanha, e os objetivos secundários foram: observar, a partir das resenhas analisadas, se o uso de "experimentação" na Alemanha tem uma grande variedade de técnicas, se há uma recepção favorável desses elementos experimentais pelo público alemão e/ou se os críticos avaliam negativamente a sua utilização. No projeto, apresentamos ainda duas hipóteses: a de que as encenações brasileiras de Shakespeare apresentariam menos exemplos de experimentação e a de que os elementos concretos de experimentação, tanto em um país quanto em outro, baseiam-se, em sua maioria, em técnicas já desenvolvidas e utilizadas ao longo do século XX.

A análise foi feita através de resenhas publicadas pela imprensa nos dois países, e completada com encenações assistidas em vídeo (duas montagens alemãs) e no teatro (uma montagem brasileira). Foi realizada, ainda, uma comparação entre as anotações dessas encenações e as resenhas publicadas dos respectivos espetáculos. A análise do estudo foi feita em três níveis: quantitativo, qualitativo e da qualidade de recepção. No primeiro caso, levantamos os elementos experimentais e convencionais de acordo com os conceitos estabelecidos na pesquisa e mencionados pelos resenhadores. No segundo, listamos os elementos mencionados pelo resenhador, classificados como experimentais, que pudessem ser acrescentados à lista estabelecida no projeto. No terceiro, analisamos a avaliação da experimentação segundo o crítico, bem como as suas referências em relação à sua repercussão junto ao público.

Infelizmente não poderemos tratar aqui de todos os pontos abordados na pesquisa, mas apresentaremos alguns, que consideramos relevantes, para a proposição da reflexão sobre o tema desse artigo: o conceito de exerimentação, o conceito de convenção e a apresentação de alguns dados levantados na pesquisa.

Sendo elemento presente, porém pouco pesquisado, a experimentação no teatro contemporâneo alemão mereceu um estudo particular que foi comparado? como parâmetro? à prática teatral brasileira no mesmo período que compreendeu a análise do estudo. 


\section{O conceito de experimentação - Brecht e Artaud como ponto de partida}

Para a realização da pesquisa foi necessário o estabelecimento do conceito de experimentação. Conforme indicamos no capítulo anterior, partimos dos elementos contidos no texto e sua transposição cênica, ou seja, consideramos "experimentais" todos os elementos da encenação que divergem dos apresentados no texto dramático original (os registros do dramaturgo: extra-diáologos e/ou narrativa). Com esse objetivo, adotamos as práticas conceituais estabelecidas por Antonin Artaud e Bertolt Brecht, que propuseram novas formas de teatralização que? embora realizadas de maneiras diferentes?, no estudo, categorizamos como experimentais. Complementarmente a ela, consideramos experimentais os elementos que remetem às práticas de Brecht e Artaud.

Artaud entende a encenação como uma forma de linguagem material (física, palpável, visível) a ser adotada pelo encenador: "Não está de modo algum provado que a linguagem das palavras deve lugar à linguagem pelos signos, cujo aspecto objetivo é aquilo que de modo mais imediato nos atinge" e, ainda, "[...] além de uma representação com meios materiais e espessos, a encenação pura contém, através de gestos, jogos fisionômicos e atitudes móveis, através de uma utilização concreta da música, tudo aquilo que a palavra contém e, além disso, dispõe da própria palavra"(ARTAUD 1987: 137 e 153).

Para Brecht, o teatro está interessado, antes de tudo, no comportamento que os homens adotam uns diante dos outros, sempre que forem comportamentos significativos social e historicamente: "A realidade se modifica: para representá-la é necessário modificar também os meios de representação" (BRECHT 1967: 119). Para o dramaturgo e diretor alemão, o teatro não deve proporcionar apenas as sensações e os impulsos que são permitidos pelo respectivo contexto histórico (o contexto em que as ações se realizam), mas sim que empregue e suscite pensamentos que desempenhem um papel na modificação desse contexto. Tal contexto tem de poder ser caracterizado na sua relatividade histórica.

Para fazer o levantamento dos elementos de experimentação nas resenhas, estabelecemos, heuristicamente, uma lista de elementos experimen- 
tais, de acordo com a fundamentação teórica desses dois autores. Arrolamos, então, alguns elementos apresentados por Brecht e Artaud: a utilização do gesto como linguagem substitutiva do texto; a transposição da fala da $1^{\mathrm{a}}$ para a $3^{\mathrm{a}}$ pessoa do singular; a caracterização do ator e/ou personagem (ausência de coxia, caracterização parcial ou divergente da proposta no texto original, etc.); a utilização da música como elemento de substituição do texto; a utilização da música como recurso de distanciamento, tanto do espectador como do ator; a utilização de recursos visuais (ex: cartazes, filmes, fotografias, obras de arte, etc.); a capitulação de cenas (apresentação titular das cenas antes delas ocorrerem). Completamos essa lista com elementos que remetem às práticas de Artaud e Brecht, e que são: a inclusão e/ou exclusão de novos personagens no texto dramático e na montagem; a forma de realização das rubricas ou a não realização das mesmas; a interatividade entre público e atores; a intertextualidade - a citação de frases, ou trechos de outro autor ? na montagem de Shakespeare; a presença de um prelúdio, não pertencente ao texto dramático, na montagem; a exclusão de trechos do texto na montagem, talvez obedecendo a uma tradição de cortes de cenas dispensáveis; o ator, na representação, fazer reflexões acerca do texto ou da prórpia representação, ou, ainda, da sociedade (ex: gestos que divergem das ações propostas pelo autor no texto dramático, etc.).

Os dados levantados na pesquisa mostraram-nos três necessidades para a elaboração do relatório final da pesquisa: 1) a de acrescentar dois elementos de experimentação, colhidos nas resenhas analisadas e que remetem às práticas descritas como experimentais, que são: o deslocamento das ações na peça do centro para as paredes do palco e a linguagem utilizada na encenação, fornecida pela tradução que é feita do texto; 2) a de aprofundar o conceito de experimentação trabalhado no estudo e 3) a de direcioná-lo apenas para a prática brechtiana. A primeira deu-se pelo que havíamos previsto no projeto, a segunda deu-se porque não seria possível realizar uma análise das formas de experimentação apenas recortando os elementos levantados pelo dramaturgo alemão e a terceira foi devido ao fato de que a maioria das resenhas apresentavam elementos experimentais que convergiam para os seus pressupostos. Naquele momento, tornou-se necessário, ainda que de forma breve, pontuar algumas questões acerca da teoria de Brecht, pois consideramos que os elementos de distanciamento 
estão inseridos dentro dela com o objetivo de colocar em prática a sua concepção sobre o teatro.

Muitas reflexões de Brecht foram baseadas em seus questionamentos sobre a função do teatro, bem como a possibilidade de sua realização na época em que vivia. Ele desenvolveu o Teatro Épico que, em suas palavras,

[...] é um teatro vincado de caráter estético; denota um conteúdo complexo e, além disso, profunda preocupação social [...]. O exemplo-padrão [de uma encenação] tem importância prática. Dá aos diretores de ensaio e aos atores que prepararem uma representação nesses moldes, em que surjam questões de pormenor frequentemente complexas e problemas artísticos e sociais, a possibilidade de controlarem se a função social de toda a engrenagem se mantém perfeitamente intacta. (BRECHT s.d.: 127).

Pensando ainda no caráter estético do teatro, o dramaturgo alemão adota o efeito de distanciamento que tinha como função "distanciar o 'gesto social' subjacente a todos os acontecimentos. Por 'gesto social' deve-se entender a expressão mímica e conceitual das relações sociais que se verificam entre os homens de uma determinada época." (BRECHT s.d.: 182). A proposta de Brecht estabeleceu, assim, a mudança da função do teatro que passou, especialmente a partir de seus pressupostos, a ter uma função social.

Então, a utilização da técnica de distanciamento é tida como uma forma de instrumentalização para atingir esse objetivo, ou seja, os elementos apresentados por Brecht também tinham funções determinadas na estética do teatro épico e por isso não faz sentido serem aplicados sem levar em conta as relações entre palco e público, texto e representação, diretor e atores e, principalmente, o fornecimento de uma perspectiva crítica.

Outro elemento importante na constituição do teatro épico era o texto. Sobre ele, Bornheim afirma que "Brecht nada tem a ver com o elogio de um gênero literário, e sim com a função que um texto possa oferecer - se autonomia há, deve-se discutir seu caráter, o seu modo de ser dentro da totalidade do espetáculo", e, ainda, que o dramatugo "só poderia ser contrário à hegemonia do texto em relação à montagem. Para ele [Brecht] é 
falha a concepção do texto em si, ao qual acrescentar-se-iam, num segundo momento, as 'idéias' possíveis sobre sua encenação [...]” (BornHEIM 1992: 161-162 e 309).

Bornheim afirma ainda que o fenômeno teatral deve apresentar, portanto uma unidade de raiz, e essa unidade já se encontra garantida na plasticidade que se empresta ao tratamento da língua, e que, de certa forma, o texto escrito como que antecipa em si o espetáculo. "Assim, a plasticidade do texto compõe-se juntamente com os recursos de que lança mão a encenação" (BORNHEIM 1992: 57).

Desta forma, tanto os elementos de distanciamento quanto a (re)elaboração de um texto eram instrumentos para Brecht atingir a "relatividade histórica" que fundamentava a estética de seu teatro. Como a pesquisa tratou de montagens de textos shakespeareanos, cabe aqui apontar a relação que Brecht estabeleceu com os textos clássicos,

Ele [Brecht] se aproxima dos clássicos sem ressentimento, mas também sem intimidação, no que procura fazer ressaltar o caráter problemático de seus esforços, o que tem de proeza mas também o que tem de limitação. Este efeito, ele o obtém ? dito de maneira geral ? historicizando a obra clássica, o que se dá no sentido mais forte do termo, recuperando-a no conjunto de contradições sociais em que se produz e que nela se exprime. (PASTA JR. 1986: 128)

Alguns exemplos de textos clássicos que Brecht reelaborou para o palco são: Antígona de Sófocles, Der Hofmeister (O Preceptor) de Lenz, Urfaust de Goethe, Eduardo II de Marlowe, e Coriolano de Shakespeare, que ficou inacabado devido à morte do dramaturgo alemão.

\section{O conceito de convenção}

No estudo, em contraposição ao conceito de experimetação, foi necessário estabelecer o conceito de convenção, que foi constituído a partir dos pressupostos teóricos de Constantin Stanislavski, assim como de elementos que 'envolvem' o espectador nas ações apresentadas em cena, ou seja, os elementos convencionais são aqueles que conservam as formas de apre- 
sentação do teatro burguês do século XIX e que procuram reproduzir nas transposições cênicas, senão fielmente, com uma grande aproximação, os registros apresentados pelo dramaturgo (extra-diálogos e/ou narrativa) e que criam um efeito de ilusão no espectador, fazendo com que ele vivencie o espetáculo do mesmo modo que os atores, quando representam os personagens.

Stanislavski utilizou-se de elementos que permitiam a realização de um teatro realista e que proporcionavam ao espectador uma experiência, senão idêntica, muito próxima à vida real. $\mathrm{O}$ fato de uma das matérias do teatro ser o ator, muitos de seus pressupostos estão pautados na forma de representar. Outro elemento importante para ele é a caracterização física do artista, pois "[ela] é a máscara que esconde o indivíduo-ator. Protegido por ela, ele pode despir a alma até o último, o mais íntimo detalhe. Esse é um importante atributo ou traço de transformação" (STANISLAVSKI 1970: 43).

Assim, estabelecemos, também heuristicamente, uma lista de elementos convencionais que proporcionam um maior envolvimento do espectador nas ações da peça e que criam um efeito de ilusão, que são: os atores devem se dirigir aos outros atores e não aos espectadores; o cumprimento das "circunstâncias dadas" pelo autor do texto (ex: os cenários, os trajes, os acessórios, os efeitos de luz e som, que, segundo Stanislavski, levam o ator à elaboração do papel); as rubricas serem apresentadas tais e quais descritas pelo autor; a apresentação do texto na íntegra; a iluminação do palco (claro) e público (escuro), efeito que leva o espectador para 'dentro' da montagem, ou seja, a presença de uma 'cortina' entre atores e platéia; a reprodução exata, ou muito próxima dos espaços descritos nos textos com a presença de objetos de cena, bem como os figurinos que representam, ou buscam representar, o contexto histórico apresentado no texto; a caracterização dos personagens, ou ainda, a representação feita para o público com a finalidade de associar o ator ao personagem, criando uma só pessoa; a música na montagem utilizada com a finalidade de nortear o público para o contexto histórico dado pelo autor, e também quando é utilizada para iludir, ou ainda, envolver o público no drama vivido pela personagem. 


\section{旁 4 . Apresentação de alguns dados da pesquisa e comentários sobre a análise}

$\sim$

ก

Foi realizada a análise de 16 montagens: 9 alemãs e 7 brasileiras, incluindose as encenações assistidas em vídeo e no teatro. A análise baseou-se em seis textos de Shakespeare: Macbeth, Hamlet, Rei Lear, Sonho de uma Noite de Verão, A Tempestade e Otelo. No caso de Macbeth, analisamos 5 montagens (duas em cada país através das resenhas, e uma alemã através de uma fita de vídeo), no caso de Sonho de uma Noite de Verão, analisamos 3 montagens (uma em cada país através das resenhas e uma alemã através do vídeo), e a montagem brasileira de Otelo foi assistida no teatro. As peças assistidas em vídeo e no teatro também tiveram suas resenhas analisadas e comparadas às anotações feitas dos respectivos espetáculos. O critério para a escolha desses textos shakespeareanos deu-se pelo número de resenhas encontradas para cada montagem quando houve o recolhimento do corpus para o estudo.

Para a realização do levantamento dos dados, estabelecemos uma tabela ${ }^{1}$ para cada montagem, onde apresentamos os elementos - convencionais e/ou experimentais - mencionados pelos resenhadores. Além de anotar a menção dos elementos nessas tabelas, indicamos se houve, por parte do resenhador, uma avaliação positiva ou negativa desses elementos. Embora apresentem um material riquíssimo para a análise, como, por exemplo, a forma como a crítica de uma peça teatral é formulada em cada país, o objetivo central da pesquisa era fazer um levantamento dos elementos experimentais nos dois países, com um enfoque nas montagens alemãs. Por esse motivo, nos detivemos apenas a esse objetivo quando analisamos as resenhas.

Foram lidas 23 resenhas alemãs e 19 resenhas brasileiras ${ }^{2}$. Os elementos experimentais, estabelecidos heuristicamente no início do estudo, foram mencionados 104 vezes no número total das resenhas alemãs lidas, enquanto que nas brasileiras houve 46 menções nas 19 resenhas brasileiras lidas. Os elementos convencionais foram mencionados 24 vezes nas rese-

Ver modelo (tabela e uma resenha) no anexo desse artigo.

A descrição do corpus analisado está no anexo desse artigo. 
nhas brasileiras, enquanto as alemãs apresentaram 4 menções. Cabe aqui dizer que as menções se dão no relato/descrição da peça, quando o resenhador aponta, por exemplo, a inclusão de uma cena (não pertencente ao texto original), o uso da linguagem (tradução, uso de algum dialeto, ambientação da história para os dias atuais, etc.), ou a 'fidelidade' da montagem em relação ao texto shakespeareano.

A partir desse levantamento, cumprimos o objetivo central do projeto, que era a realização de uma amostra dos elementos experimentais nas encenações de textos shakespea-reanos nos dois países no período que compreendeu o estudo. Esse levantamento nos impele a abordar alguns pontos, que consideramos importantes, acerca dessa experimentação: as técnicas (experimentais) usadas nas montagens de Shakespeare nos dois países, a forma como elas são usadas (se são usadas mais ou menos na Alemanha e no Brasil, assim como as suas funções dentro do espetáculo) e a avaliação do público (pelo filtro do resenhador) e dos críticos em relação a elas.

Antes de abordá-los, vale anotar que a presença em maior número de elementos experimentais em uma encenação não mostra que essas montagens apresentem apenas esses elementos, pois, por se tratar de teatro, torna-se claro que o encenador utilizará também elementos convencionais para envolver o seu público. Anotamos, ainda, que as resenhas não dão conta de apresentar todos os elementos de uma montagem, quer sejam experi-mentais, quer convencionais, pois o próprio formato do texto, que deve ser sucinto, apresenta-se em jornais ou revistas, mas, apesar disso, mostraram-se um instrumento eficiente para o cumprimento do objetivo central da pesquisa feita.

Em relação às técnicas experimentais usadas nas montagens de textos shakespeareanos, o levantamento feito indica que elas convergem para as técnicas de distanciamento brechtianas, ou seja, o que os resenhadores indicam como experimentação não apresenta técnicas novas, mas está fundamentada em outras já desenvolvidas ao longo do século XX, conforme foi postulado no início desse texto. Também torna-se clara a necessidade de relativizar um termo usado na apresentação dos objetivos secundários da pesquisa: "uso de 'grande' variedade de técnicas", pois se as técnicas são as mesmas usadas por Brecht, elas recaem apenas sobre um teórico, e, além 
disso, pelo que observamos nas resenhas analisadas, não são usadas todas juntas em uma única montagem. Nesse momento, cabe uma reflexão acerca do conceito (geral?) de experimentação, pois observamos com esse levantamento que, nos dias de hoje, ele não é sinônimo de inovação, e partimos da seguinte questão: Será que Brecht pode ser considerado experimental, no sentido de inovar as formas de representação, em sua época? Indicamos duas respostas: sim e não. Se fizermos apenas um recorte das técnicas não só de representação, mas também da elaboração dos textos, o próprio Brecht em sua obra Estudos sobre o Teatro aponta que muitas técnicas utilizadas para o "efeito de distanciamento" foram apreendidas do teatro chinês e que as partes de uma fábula deveriam ser contrapostas para apresentar uma peça dentro da peça. Nesse sentido, ele não apresentou inovações na forma de representação, mas sedimentou sua práxis em outras já existentes. Porém, conforme indicamos, em Brecht não é possível apenas recortar a forma de representação, é necessário apresentar o conteúdo, ou seja, a função desses elementos na encenação. Sobre isso, o dramaturgo comenta que

a forma de representação épica não poderá ser indiscriminadamente utilizada para todas as obras clássicas. Creio que é sobretudo fácil empregá-las, isto é, que dentre todas é esta a forma que parece asseverar melhores resultados em relação às peças como as de Shakespeare ou às primeiras obras dos nossos clássicos (o Fausto inclusive). Mas tudo depende do caráter da função social da obra, função essa que deverá ser a de uma reprodução da realidade destinada a exercer influência sobre essa mesma realidade. (BRECHT s.d.: 291-292)

Nesse sentido, consideramos que a inovação de Brecht aconteceu devido à modificação da função da obra de arte, que passou, a partir dos seus pressupostos, a ter uma função social.

Antes de falar sobre como esses elementos experimentais foram usados - de acordo com os apontamentos dos resenhadores na Alemanha e no Brasil - nas montagens contemporâneas, gostaríamos de pontuar uma questão relevante. A partir das resenhas analisadas, observa-se que os elementos experimentais são mencionados mais vezes nas encenações alemãs do que nas brasileiras e que com os elementos convencionais isso se inver- 
te. Não fazia parte do projeto, e tampouco seria pertinente nesse momento, averiguar a causa disso, mas dentro de nossa reflexão, abrimos um leque de possibilidades desse fenômeno: as diferentes tradições teatrais nos dois países, a recepção de Shakespeare no Brasil e na Alemanha ou, ainda, a tradução que é feita dos textos nos dois países estudados.

Para a apresentação da forma de apropriação desses elementos pelos encenadores contemporâneos, comentaremos alguns pontos da análise qualitativa da recepção, ou seja, dos resenhadores ou as referências sobre sua repercussão junto ao público. $\mathrm{Na}$ maior parte das resenhas alemãs, observou-se que os elementos experimentais são bem avaliados pelo resenhador quando cumprem uma função na atualização do clássico, ou seja, quando contribuem com o fio condutor dado pelo diretor através do texto. Um exemplo disso é a resenha do Frankfurter Allgemeine Zeitung escrita por Renate Schostak sobre a montagem de Otelo dirigida por Luk Perceval. Ela afirma que o encenador tem um modelo de desconstrutivismo e que, no lugar da realidade, parte da mediação e deixa ajustar qualquer peça a esse esquema, mas afirma que a partir do uso de jargões e do "Kanaksprak", pode-se reconhecer, na adaptação do diretor e tradutores, a denúncia de um Shakespeare racista, imoral, sexista e misógino. Ou, ainda, na resenha da revista Theater heute, escrita por Michael Merschmeier, sobre a montagem de Macbeth do Teatro Livre de Munique, onde o autor indica que a execução de um Weihespiel - peça sagrada, alusão ao "Parzival" de Wagner - poderia dar errado, mas que no caso dessa montagem entretém com muita arte, com uma mistura de teatro dançado e interpretado; e, ainda, que as falas cantadas e acusticamente coreografadas - solos, duetos e cânones alcançam uma força anti-trágica (assistimos a essa montagm em vídeo e as falas cantadas e as coreografias eram a marca dada pelo encenador à montagem).

A crítica ao uso desses elementos é feita quando o resenhador aponta que houve o uso excessivo deles, ou, ainda, quando os elementos não têm uma função no fio condutor da montagem. Apresentamos como exemplo disso a resenha do Neue Zürcher Zeitung, escrita por Barbara Villiger Heilig, onde, ao descrever o cenário da monagem de Hamlet dirigida por Uwe Erich Laufenberg, a autora afirma que a cenografia reúne no palco um design dos anos pós-guerra e, com a ajuda de espelhos, efeitos de luz e monitores de 
televisão dispostos em níveis, faz uma mistura medíocre (“durchschnittlichen”) de instalações de mídia.

Nas montagens brasileiras, os elementos experimentais são bem avaliados pelos resenhadores que também apresentam a indicação de sua boa aceitação por parte do público, e, embora as resenhas não indiquem de que forma eles contribuem com uma função dentro do espetáculo, muitos resenhadores afirmam que o uso desses elementos atualizam o clássico. Um exemplo disso é a resenha sobre a montagem de Macbeth, dirigida por Ulisses Cruz, onde o resenhador Apoenan Rodrigues afirma que "a modernidade da tradução, adaptação e encenação de Ulisses Cruz começou pela decisão drástica de Fagundes [ator que interpretou Macbeth] de raspar seus cabelos grisalhos [...]" emprestando ao cruel personagem "um ar hard e underground"' Embora ele faça uma avaliação positiva da montagem e desses elementos ao longo da resenha, deixa de abordar o motivo da atualização do texto, assim como a função da caracterização do ator que interpreta Macbeth. Apresentamos uma consideração sobre algumas indicações que observamos nas resenhas: nas alemãs, pode-se notar uma preocupação dos críticos em relação ao 'reconhecimento' do clássico, ou seja, apesar do uso de recursos experimentais na montagem e/ou no texto (contextualização histórica) é necessário, para os resenhadores, que o clássico não perca os traços fundamentais que o compõem; nas resenhas brasileiras, é refletida a "preservação" do clássico, ou seja, os críticos enfatizam e avaliam positivamente a montagem que apresenta um texto na íntegra e com uma tradução literal do texto shakespeareano - sem fragmentação no uso da linguagem, sem dialetos, sem intertextualidade, ou, ainda, um texto que não inclua ou suprima trechos do original shakespeareano.

Ainda sobre a apropriação desses elementos experimenatis nos dias de hoje, apresentamos como exemplo a montagem de $A$ Tempestade dirigida por Christian Weisse e Christian Tschirner e apresentada no Schauspiel Köln, que suscitou um importante indicativo do uso desses elementos na contemporaneidade. Os resenhadores relatam que nessa montagem os recursos visuais (filmes e slides) são usados, mas nota-se que eles criam a atmosfera da ilha, mostrando "noites estreladas e cenas submarinas", ou

3 "Shakespeare Radical" - Jornal do Brasil - 26.01.1992. 
seja, não buscam distanciar, mas sim envolver o público. Outro exemplo disso é a montagem de Otelo dirigida por Luk Perceval, que, embora apresente um pianista de jazz que fica em cena durante todo o espetáculo (à vista do público como Brecht sugere), toca músicas que acompanham todos os momentos de tensão das ações na peça, ou seja, fornece um envolvimento maior do público nessas ações.

A partir desses exemplos, vale considerar que o efeito de distanciamento foi uma solução encontrada pelo dramaturgo alemão que, dentro da proposta de historicizar o clássico e mudar a função do teatro, buscou proporcionar ao espectador uma visão crítica sobre as ações que via em cena. Esta solução serviu ao contexto histórico em que Brecht viveu, porém, nos dias de hoje, quando os encenadores apenas reproduzem alguns desses recursos sem se valerem da proposição crítica e da mundança da função da obra de arte, propostas por ele, eles criam, muitas vezes, o efeito contrário ao proposto pelo dramaturgo alemão, ou seja, o envolvimento do público nas ações representadas sem fornecer a reflexão do porquê da escolha de determinado texto para um momento político e/ou social, e qual o seu papel (do público) dentro da mudança do contexto em que esse texto é representado.

\section{Considerações finais}

Seria imprudente tentar responder às questões que nortearam a realização da pesquisa e que apresentamos no início desse artigo, ou seja, a definição do conceito maior de experimentação, definir a contemporaneidade para o teatro e a experimentação dentro dessa contemporaneidade, porque elas foram uma motivação da realização do estudo e não o objeto dele, mas a partir delas buscaremos traçar algumas linhas, à guisa de conclusão, acerca de nossa reflexão sobre o tema. Os dados levantados no estudo indicam que os recursos de experimentação, estabelecidos na pesquisa e usados nas montagens de textos shakespeareanos na Alemanha e no Brasil após 1990 até os dias atuais são os mesmos estabelecidos por Bertolt Brecht, portanto, conforme afirmamos, não trazem algo de inovador, mas são técnicas usadas e sedimentadas ao longo do século XX, e, a partir disso, concluímos apenas que experimentação não é inovação. 
Em relação à contemporaneidade, recorremos a Brecht para refletir sobre sua importância no teatro, e ele afirma o seguinte,

Necessitamos de um teatro que não nos proporcione somente as sensações, as idéias e os impulsos que são permitidos pelo respectivo contexto histórico das relações humanas [o contexto em que as ações se realizam], mas sim, que empregue e suscite pensamentos que desempenhem um papel na modificação desse contexto. Tal contexto tem de poder ser caracterizado na sua relatividade histórica. ${ }^{4}$ (BRECHT s.d.: 182).

A partir da apropriação dos elementos experimentais/brechtianos na nossa contemporaneidade, indicados nas resenhas analisadas e ilustrados em alguns exemplos que apresentamos, observa-se que quando eles não são bem avaliados pelos resenhadores por não apresentarem uma função na peça ou, ainda, por não contribuírem com o fio condutor dado à atualização da peça clássica, são meras reproduções das técnicas de distanciamento propostas pelo alemão, e não levam em conta o todo de sua teoria, ou seja, a perspectiva crítica a serviço de uma mudança na função da obra de arte e, conseqüentemente da sociedade.

Embora parte das técnicas apresentadas por Brecht sejam, nos dias de hoje, apenas reproduzidas, esse dado indica a atualidade do dramaturgo alemão, e sobre ela o crítico Roberto Schwarz, em uma palestra proferida em junho de 1997 no Teatro de Arena Eugênio Kusnet, afirma que "esse conjunto de teses e proposições, de soluções técnicas em que se move o teatro de Brecht mudou muito de sentido na história recente. O impacto, o significado dele historicamente se alterou". (SCHWARZ 1998: 28-36). O crítico ainda diz que o quadro histórico em que funciona a operação do distanciamento está mudado, e que é necessário reinventar o distanciamento de maneira a transformá-lo em uma potência crítica, e não mistificar essa direção, ou seja, a utilização desses recursos. Quando Schwarz apresenta essas questões, ele não só aponta a necessidade de mudança das práticas brechtianas para ajustá-las a nossa contemporaneidade? diga-se de passagem, algo proposto pelo próprio alemão?, mas também rememora o pró-

4 Grifo meu. 
prio fundamento da teoria de Brecht, que se baseou no questionamento sobre a função do teatro na contemporaneidade. Brecht encontrou algumas soluções para sua época, resta que nós encontremos as nossas, sem nos esquecermos, é claro, da questão que fundamentou a teoria proposta pelo dramaturgo alemão: qual é a função do teatro hoje?

\section{Referências bibliográficas}

Artaud, Antonin. O teatro e seu duplo. São Paulo, Max Limonard 1987.

BornheIM, Gerd. Brecht: a estética do teatro. São Paulo, Graal 1992.

Brecht, Bertolt. Teatro Dialético. Rio de Janeiro, Civilização Brasileira 1967. Bertolt. Estudos sobre Teatro: para uma arte dramática não-aristotélica. Lisboa, Portugália Sem data.

Lehmann, Hans-Thies. "Tradition and the postdramatic talent", "Das Neue, die Avantgarde", "Theater nach Brecht". In: LeHmann. Postdramatisches Theater: Essay. Frankfurt am Main, Verlag der Autoren 1999.

Pasta Jr. José Antônio. Trabalho de Brecht. São Paulo, Ed. Ática 1986.

Ryngaert, Jean-Pierre. Ler o Teatro Contemporâneo. São Paulo, Martins Fontes 1998.

Rosenfeld, Anatol. Teatro Alemão. São Paulo, Brasiliense 1968.

SCHWARZ, Roberto. "A atualidade de Brecht". In: Revista do "Vintém”, Ed. Hucitec, No 1, março de 1998.

Stanislavski, Constantin. A Construção da Personagem. Rio de Janeiro, Civilização brasileira 1970. 


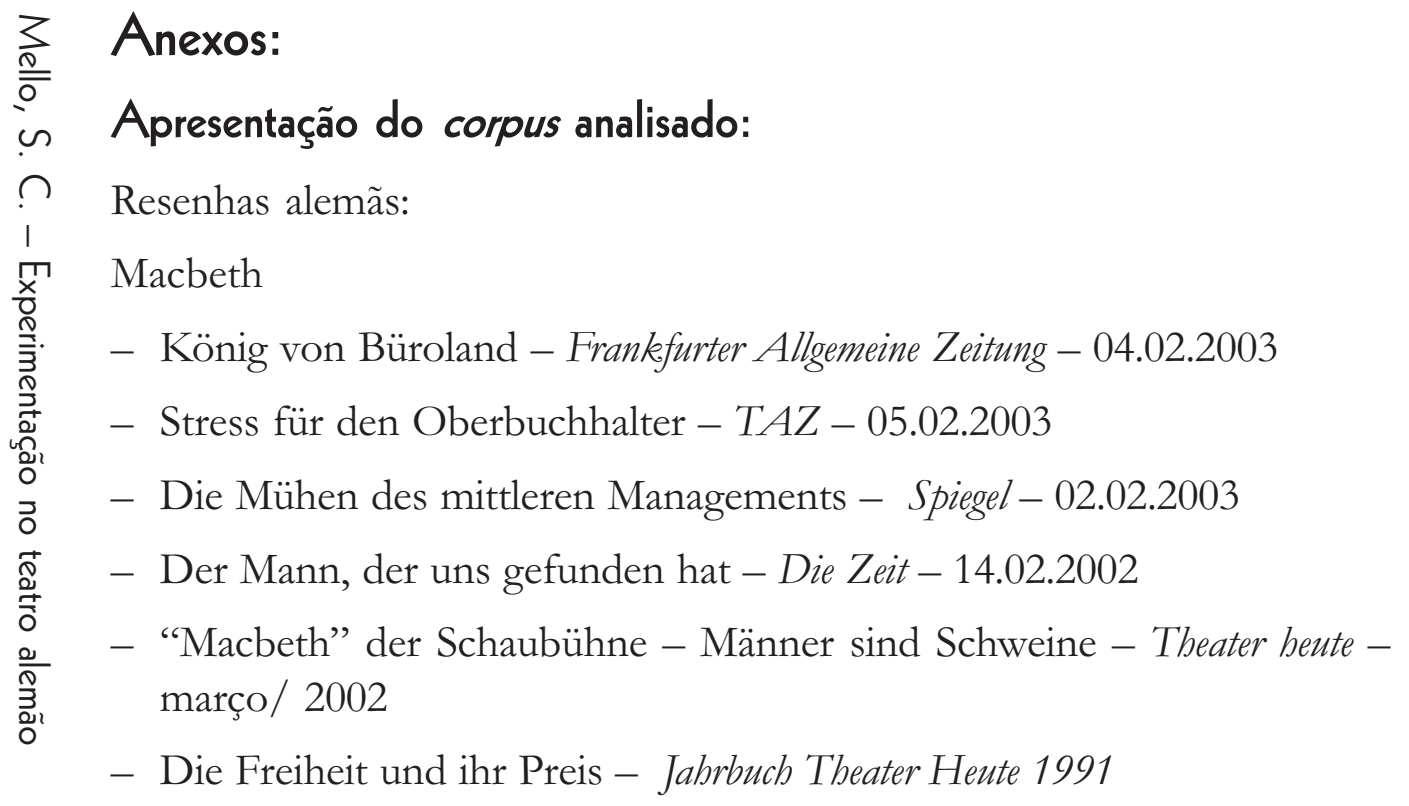

\section{Hamlet}

- Speck für die Poltergeister der Maschinenmäuse - Frankfurter Allgemeine Zeitung - 04.02.1997

- Looking for Hamlet - Neue Zürcher Zeitung - 03.02.1997

\section{Otelo}

- Othello München / Mann der kleinen Möglichkeiten - Frankfurter Allgemeine Zeitung - 04.02.1997

- Der General und das Mädchen - Neue Zürcher Zeitung - 31.03.2003

- Liebe in Schwarz und Weiß - Frankfurter Rundschau - 31.03.2003

- Schoko, Weiß - Süddeutsche Zeitung - 31.03.2003

- Der alte Tor und das Mädchen - TAZ - 02.04.2003

- Ein Mann sieht Schwarz - Die Zeit - 03.02.2003 
A Tempestade

- Steif für die Insel - Süddeutsche Zeitung - 28.12.2002

- Puppensturm - Frankfurter Allgemeine Zeitung - 31.12.2002

Rei Lear

- Lear ohne Last: Heyme inszeniert Shakespeare in Madrid - Frankfuter Allgemeine Zeitung - 22.01.2002

- Lear - Inszenierung von Heyme in Madrid - Frankfurter Rundschau 21.05.2003

Sonho de uma Noite de Verão

- Pop macht depressiv - Frankfurter Allgemeine Zeitung - 04.10.2000

- Geklonte Hippies und der Hype - Neue Zürcher Zeitung - 02.10.2000

- Vor der Premiere - Neue Zücher Zeitung - 29.09.2000

- Verstehst du mich- Ich dich nicht! Karin Beiers Euro-Shakespeare im Düsseldorfer Schauspielhaus - Süddeutsche Zeitung - 03.11.1995

- Gemeinsame Zunge oder Europa spricht Shakespeare. Düsseldorf: Ein polyglotter "Sommernachtstraum" auf der Bühne - Berliner Zeitung 06.11 .1995

\section{Resenhas brasileiras:}

Macbeth

- Antunes põe Macbeth contra a parede - O Estado de São Paulo-11.05.1992

- "Trono de Sangue / Macbeth" é a purgação da maldade de todos - Folha de São Paulo - 23.05.1992

- Montagem desfoca "Macbeth" entre trevas e névoa - Folha de São Paulo 25.03.1992

- Shakespeare Radical - Jornal do Brasil - 26.01.1992 


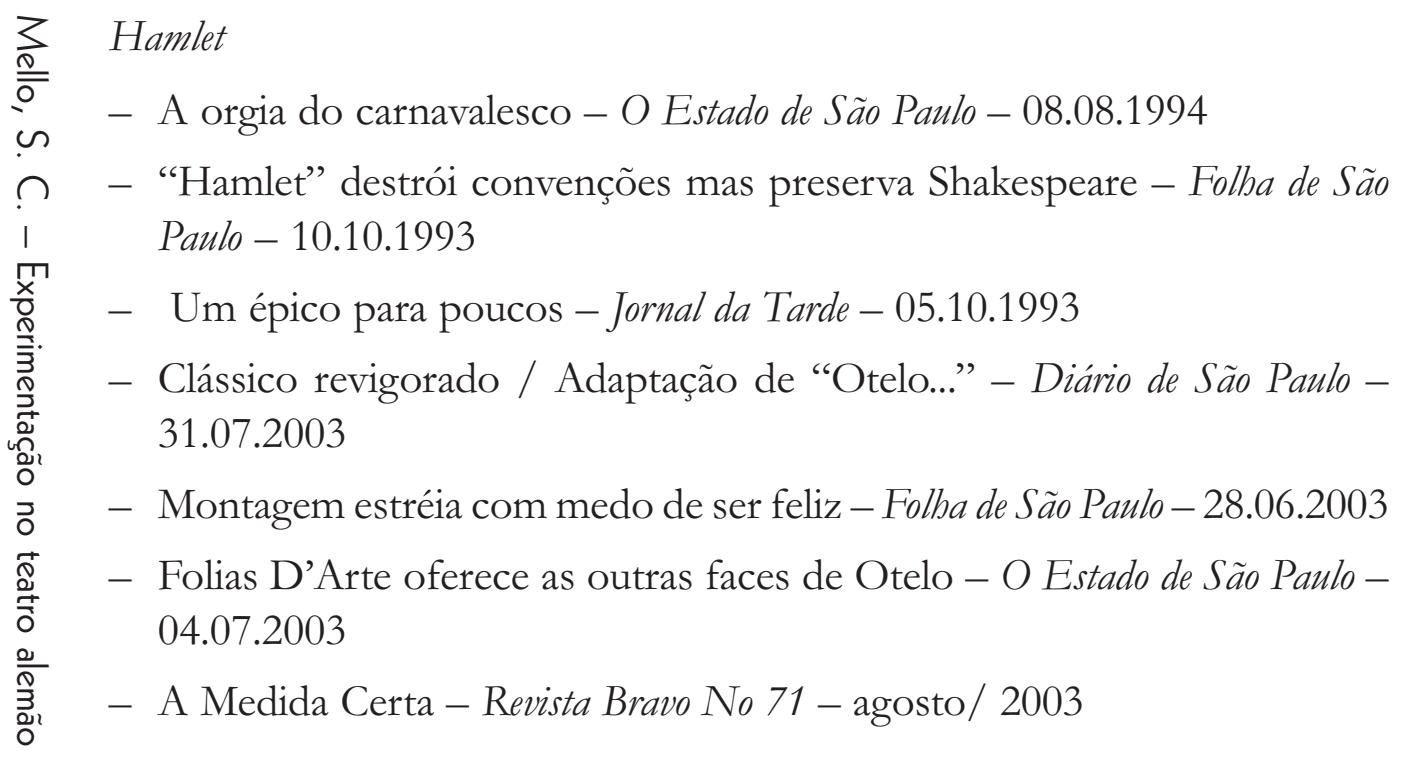

A Tempestade

- "A Tempestade" na versão lúdica do XPTO - O Estado de São Paulo 14.11.2002

- Próspero conciliador ganha cores do XPTO - Folha de São Paulo 14.11.2002

- "A Tempestade" deixa o XPTO a ver navios - O Estado de São Paulo 06.12 .2002

Rei Lear

- 'Rei Lear traz Raul Cortêz na medida certa - O Estado de São Paulo 08.09.2000

- Rei Lear - Folha de São Paulo - 23.08.2000

Sonho de uma Noite de Verão

- Rosset vai do lírico ao bufão em "Sonho" - Folha de São Paulo - 16.01.1992

- "Sonho" retoma o prazer através do riso - Folha de São Paulo - 18.01.1992

- Rosset e Vilela fazem o teatro dos sonhos - Folha de São Paulo-29.01.1992 


\section{Vídeos analisados:}

- Macbeth - Freies Theater München

Direção: George Froscher e Kurt Bildenstein

* Cópia editada em 1993, e disponibilizada no Instituto Goethe de São Paulo.

- Sonho de uma Noite de Verão - Düsseldorf Schauspielhaus

Direção: Karin Beier

* Cópia editada em 1995, e disponibilizada no Instituto Goethe de São Paulo.

Peça assistida no teatro:

- Otelo - Grupo Folias D’Arte

Direção: Marco Antônio Rodrigues

* Temporada de 2003 e 2004 realizadas na sede do grupo, teatro Galpão do Folias em São Paulo. 


\begin{tabular}{|c|c|c|}
\hline & $\mathrm{SZ}$ & FR \\
\hline \multicolumn{3}{|l|}{ Elementos Convencionais } \\
\hline Linguagem & $\mathrm{X}(+)$ & $\overline{\mathrm{X}(+)}$ \\
\hline \multicolumn{3}{|l|}{ Elementos Experimentais } \\
\hline Exclusão/ Inclusão de passagens & $\mathrm{X}$ & $\mathrm{X}$ \\
\hline Linguagem & $\mathrm{X}$ & $\mathrm{X}$ \\
\hline $\begin{array}{l}\text { Contextualização } \\
\text { cenas/espaço/texto }\end{array}$ & $\mathrm{X}$ & $\mathrm{X}$ \\
\hline Caracterização personagens & $\mathrm{X}$ & $\mathrm{X}$ \\
\hline Cenário & $\mathrm{X}$ & $\mathrm{X}$ \\
\hline Música & $\mathrm{X}$ & $\mathrm{X}$ \\
\hline Projeção de filmes & $\mathrm{X}$ & $\mathrm{X}$ \\
\hline \multicolumn{3}{|l|}{ Recepção } \\
\hline Recepção pelo público & 0 & 0 \\
\hline Avaliação do resenhador & $(+)$ & $(+)$ \\
\hline
\end{tabular}

SZ - Süddeutsche Zeitung

FR - Frankfurter Rundschau

* O sinal $\mathrm{X}$ corresponde à menção de um elemento experimental/ convencional. O sinal 0 corresponde à ausência de menção sobre os elementos experimentais e/ou convencionais ou ainda sobre a recepção. Os sinais (+) e (-) correspondem à avaliação, respectivamente positiva e negativa, do crítico sobre os elementos apresentados e sobre a encenação. 